\title{
Feasibility and Safety of Catheter Directed Foam Sclerotherapy Combined with Tumescent Local Anesthesia for Treatment of Axial Varicose Vein Mohamed Atef Bayoumi, Mohamed Yahia Zakaria, Foad Mohamed Ahmed \\ Vascular Surgery Department, Faculty of Medicine, Al-Azhar University
}

\begin{abstract}
Background: Varicose veins is a common health problem, with an estimated prevalence of greater than $20 \%$ (range $21.8 \%$ to $29.4 \%$ ). Approximately $5 \%$ (range $3.6 \%$ to $8.6 \%$ ) have venous oedema, skin changes or ulceration. Chronic venous disease (CVD) is the most common venous disorder. It is caused by venous hypertension due to either reflux, outflow obstruction or both. Aim of the Work: The aim of the work was to review the feasibility and efficacy of catheter-directed foam sclerotherapy in treatment of saphenous vein incompetence. Patients and Methods: This clinical trial was conducted at vascular surgery department at $\mathrm{Al}$ Azhar University Hospital. The study included 25 patients suffering from primary varicose vein. All patients were belonging to class $\mathrm{C} 2$ to $\mathrm{C} 4 \mathrm{Ep}$ as Pr according to CEAP classification. This mean: $\mathrm{C} 2$ to $\mathrm{C} 4$ clinically stage to stage venous disease in which there were uncomplicated, moderate to severe varicosities. Ep etiologically the disease was primary with well functioning deep system. Anatomically, the varicosities affected the superficial system mainly the great saphenous vein. Results: Between March 2017 and March 2018, 25 patients (25 limbs) were treated with CDFS at vascular department - Al-Azhar University hospitals. Demographic data and severity of venous disease are shown in Table below. Conclusion: The use of this catheter based technique facilitated foam sclerotherapy with a high primary and acceptable short-term occlusion rates, and low numbers of complications. Further studies are required to evaluate how the migration of foam into the common femoral vein can be diminished and whether the techniques used in this study of leg elevation and manual compression provide any advantage.
\end{abstract}

Keywords: Catheter Directed Foam Sclerotherapy, Tumescent Local Anesthesia, Axial Varicose Vein.

\section{INTRODUCTION}

Varicose veins are a common health problem, with an estimated prevalence of greater than $20 \%$ (range $21.8 \%$ to $29.4 \%$ ). Approximately $5 \%$ (range $3.6 \%$ to $8.6 \%$ ) have venous oedema, skin changes or ulceration ${ }^{(1)}$.

Chronic venous disease (CVD) is the most common venous disorder. It is caused by venous hypertension due to either reflux, outflow obstruction or both ${ }^{(2)}$.

The clinical stages of varicose veins have been classified using the Clinical, Etiological, anatomical and Pathophysiological (CEAP) system. Simple varicose veins (CEAP classification C1 - C3) are more prevalent in women, with no significant gender differences being reported in the prevalence of severe varicose veins $(\mathrm{C} 4-\mathrm{C} 6)^{(3)}$.

Diagnosis of primary varicose veins was carried out depending on patient history, physical examination and duplex scanning was considered the method of choice for the investigation of venous reflux. It combines the assessment of anatomic structure and the function evaluation of blood flow to enable quantification of reflux duration in specific superficial and deep vein segments. In addition, the choice of this method was as a noninvasive and repeatable method of measurement ${ }^{(4)}$.
The treatment of primary varicose veins included conservative measures through leg elevation to reduce edema, venotonic drugs and elastic stocking. The Sclerotherapy was either traditional injection or foam sclerotherapy.

Operative measures included stripping with early and late complications. Endovenous measures included radiofrequency and laser ablation ${ }^{(5)}$.

The use of ultrasound guided foam sclerotherapy to treat varicose veins has rapidly increased during the last decade. Foam sclerotherapy is cheap, does not require anaesthesia, is effective and has an acceptable safety profile. The treatment rationale is that sclerosant agents damage the endothelium irreversibly by disrupting cell membranes resulting in sustained vasospasm and vessel obliteration.

The direct instillation of sclerosant agents as "microfoam" with air made became an attractive treatment for axial reflux in the great or small saphenous vein (GSV and SSV) ${ }^{(6)}$.

A large number of reports have documented the potential advantages of this technique for treating incompetent axial veins ${ }^{(7)}$.

\section{AIM OF THE WORK}

The aim of the work was to review the feasibility and efficacy of catheter-directed foam 
sclerotherapy in the treatment of saphenous vein incompetence.

\section{PATIENTS AND METHODS}

This clinical trial was conducted at vascular surgery department at $\mathrm{Al}$ Azhar University Hospital. The study included 25 patients suffering from primary varicose vein.

The study was approved by the Ethics Board of Al-Azhar University.

All patients were belonging to class $\mathrm{C} 2$ to $\mathrm{C} 4 \mathrm{Ep}$ as Pr according to CEAP classification. This mean: $\mathrm{C} 2$ to $\mathrm{C} 4$ clinically stage to stage venous disease in which there is uncomplicated moderate to sever varicosities. Ep etiologically the disease was primary with well functioning deep system. As anatomically the varicosities affected the superficial system mainly the great saphenous vein. Pr pathologically the disease was refluxing in nature.

\section{Inclusion criteria}

1- Symptomatic varicose vein: clinically from $\mathrm{C} 2$ to $\mathrm{C} 4$ from CEAP.

2- Incompetent great saphenous vein with diameter $5-10 \mathrm{~mm}$, measured $3 \mathrm{~cm}$ distal to the saphenofemoral junction in supine position.

3- Compressibility of GSV.

4- Intact deep vein system.

5- Reflux time of more than $1 \mathrm{~s}$ on duplex imaging.

6- Informed consent provided.

\section{Exclusion criteria}

1- Deep vein thrombosis and active superficial thrombophelebities

2- Arterial disease of lower limbs or ankle brachial index below 0.8 or both.

3- Highly tortuous GSV rending the vein unsuitable for catheter induction.

4- Pregnancy.

5- Secondary varicose veins.

6- Known allergy to polidocanol or to one of its constituents.

7- High risk of deep vein thrombosis to the following criteria:

- Oral contraceptive

- Obesity

- Smoking

- Immobility

- Malignancy

9- Patients refuse to provide a written consent for treatment and follow up.

\section{Methods}

Patient evaluation:

After informed written consent, patients were subjected to the following:

a) Clinical evaluation.

b) Duplex assessment.

Clinical evaluation was carried out for all patients according to the following scheme:

- Detailed history (disfigurement, pain, bleeding, deep venous thrombosis, anticoagulant therapy).

- Detailed general examination.

- Lower limb examination to detect:

- Distribution of veins affected.

- Incompetent perforators.

- Shape (spider, serpentine, or saccular).

Duplex was done as routine to all patients to detect:

- Patency of deep system.

- Sapheno femoral or sapheno popliteal reflux.

- Presence and number of perforators.

- Diameter of GSV and distance from the skin.

\section{Statistical analysis}

Data were analyzed using SPSS 16. Mean \pm standard deviation was computed for age, weight and height. P-value of 0.05 or less was considered statistically significant.

\section{RESULTS}

Table (1): Distribution of baseline characteristics for each of the two treatment groups.

\begin{tabular}{|l|l|c|}
\hline \multicolumn{2}{|c|}{ Age (Mean, Range) } & \multicolumn{2}{c|}{$29(\mathbf{2 3 - 3 9})$} \\
\hline \multirow{2}{*}{ Sex } & Male & $9(36 \%)$ \\
\cline { 2 - 3 } & Female & $16(64 \%)$ \\
\hline
\end{tabular}

Table (2): The distribution of baseline characteristics for each of the two treatment groups. (Mean GSV diameter)

\begin{tabular}{|l|c|}
\hline \multicolumn{1}{|c|}{ Side } & Number (\%) \\
\hline Left & $15(60 \%)$ \\
\hline Right & $10(40 \%)$ \\
\hline Unilateral & $23(92 \%)$ \\
\hline Bilateral & $2(8 \%)$ \\
\hline
\end{tabular}

Table (3): Great saphenous vein C-score

\begin{tabular}{|l|l|c|}
\hline \multirow{3}{*}{$\begin{array}{l}\text { Great saphenous vein } \\
\text { C-score }\end{array}$} & Class 2 & $11(44 \%)$ \\
\cline { 2 - 3 } & Class 3 & $8(32 \%)$ \\
\cline { 2 - 3 } & Class 4 & $6(24 \%)$ \\
\hline
\end{tabular}

Great saphenous veinC-scores are shown in the table below. 
Table (4): Primary technical success

\begin{tabular}{|l|l|c|}
\hline \multirow{2}{*}{ Primary technical success } & Yes & $19(84 \%)$ \\
\cline { 2 - 3 } & No & $6(16 \%)$ \\
\hline
\end{tabular}

Primary technical success was achieved in $19(84 \%)$ of 25 limbs.

Table (5): Post procedural complications

\begin{tabular}{|l|c|}
\hline & Number of patients \\
\hline Thrombophlebitis & $6(24 \%)$ \\
\hline DVT & $1(4 \%)$ \\
\hline Allergy & $1(4 \%)$ \\
\hline Venous ulceration & $1(4 \%)$ \\
\hline
\end{tabular}

This table shows postoperative complications.

Table (6): Patients satisfaction.

\begin{tabular}{|l|l|c|}
\hline \multicolumn{2}{|c|}{} & Number \\
\hline \multirow{3}{*}{$\begin{array}{l}\text { Patients } \\
\text { satisfaction }\end{array}$} & Very satisfied & $9(36 \%)$ \\
\cline { 2 - 3 } & Satisfied & $\begin{array}{c}13(52 \\
\%)\end{array}$ \\
\cline { 2 - 3 } & Not satisfied & $3(12 \%)$ \\
\hline
\end{tabular}

Table (7): Recanalization post operatively

\begin{tabular}{|l|l|c|}
\hline \multirow{2}{*}{$\begin{array}{l}\text { Recanalization } \\
\text { (by US }\end{array}$} & No recanalization & $\begin{array}{c}\mathbf{2 1}(\mathbf{8 4} \\
\mathbf{\%})\end{array}$ \\
\cline { 2 - 3 } Duplex) & Partial recanalization & $\begin{array}{c}3(12 \\
\%)\end{array}$ \\
\cline { 2 - 3 } & $\begin{array}{l}\text { Complete } \\
\text { recanalization }\end{array}$ & $1(4 \%)$ \\
\hline
\end{tabular}

\section{DISCUSSION}

This clinical study showed that CDFS has acceptable results in the treatment of incompetent GSV. The complication rate was low. Events such as visual disturbance, migraine or chest problems which have been previously described as following foam sclerotherapy ${ }^{(8,9,10)}$ could not be detected. The absence of early adverse effects of foam therapy may be attributed to the limited amount of foam injected in our patients.

In this study no cases of thromboembolic complications were remarked although reported in previous clinical series concerning foam sclerotherapy ${ }^{(\mathbf{8}, \mathbf{1 1})}$.

Follow-up for 6-month period showed recanalization of saphenous trunks in about $16 \%$ of duplex controlled treated limbs. This is

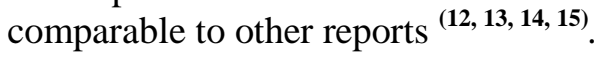

The technique that has been adopted in our study proved to be of several potential advantages. The delivering catheter itself induces venospasm resulting in a high concentration of foam as well as an optimal contact to the vein wall.
Regarding the foam itself, Cavezzi and Tessari (11) had already reported that the characteristics of home-made foam greatly influence the choice of the gas component, the liquid-to-gas ratio and the type of syringes. Larger needles are preferred for injection of foam while long catheters seem to be a valid alternative use especially when combined with tumescence to minimize the saphenous diameter. The distribution of foam achieved by direct puncture technique is unpredictable ${ }^{(16,17)}$.

Direct puncture sclerotherapy may allow larger amounts of the foam to pass into the deep

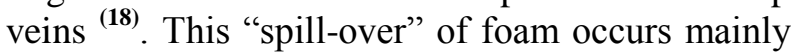
via perforators of the thigh to the deep venous system and can potentially be reduced using catheter-directed delivery into defined vesselsegments and a low injection pressure under withdrawal of the catheter ${ }^{(19)}$. However, this aspect needs further investigation.

Foam-sclerotherapy is often referred to as ultrasound-guided and controlled. This implies accuracy and safety. In most studies ultrasound is used to aid the puncture of the GSV and then to compress the saphenofemoral junction to prevent foam migration. However, the ultrasound transducer is also used to guide the foam using external massage pressure or "milking"-techniques $(\mathbf{1 2 , 8 , 2 0 , 1 3 , 2 1 )}$. In our experience using ultrasound for these purposes is technically difficult. Careful delivery of foam to the intended site of action using a sheath along the length of the axial vein is technically easier and more reliable.

The immediate success rate and the degree of reflux after 6-month follow-up of catheterdirected foam sclerotherapy was comparable well with the results of ELT or RFA treatment ${ }^{(\mathbf{9} 22)}$.

The high degree of patients` acceptance as well as the positive early results should be taken into consideration.

In conclusion, the use of this catheter based technique facilitates foam sclerotherapy with a high primary and acceptable short-term occlusion rates, and low numbers of complications. Further studies are required to evaluate how the migration of foam into the common femoral vein can be diminished and whether the techniques used in this study of leg elevation and manual compression add any advantage.

\section{CONCLUSION}

The use of this catheter based technique facilitates foam sclerotherapy with a high primary and acceptable short-term occlusion rates, and low 
numbers of complications. Further studies are required to evaluate how the migration of foam into the common femoral vein can be diminished and whether the techniques used in this study of leg elevation and manual compression provide any advantage.

\section{REFERENCES}

1- Gloviczki P, Comerota AJ, Dalsing MC et al. (2011): The care of patients with varicose veins and associated chronic venous diseases: clinical practice guidelines of the Society for Vascular Surgery and the American Venous Forum. J Vasc Surg., 53(5): 2S-48S.

2- Chiesa R, Marone EM, Limoni C et al. (2005): Chronic venous insufficiency in Italy: the 24-cities cohort study. Eur J VascEndovasc Surg., 30(4):422-9.

3- Rabe E, Guex JJ, Puskas A et al. (2012): Epidemiology of chronicvenous disorders in geographically diverse populations: results from the Vein Consult Program. IntAngiol., 31(2): 105-15.

4- Weiss RA, Weiss MA (2005): Therapy of telangiectasia and varicose veins and their complications. Textbook of cosmetic dermatology. https://www.laserskinsurgery.com/f/RW_CV_PDF_06 2014.pdf

5- Mao J, Zhang $\mathrm{C}$, Wang $\mathrm{Z}$ et al. (2012): A retrospective study comparing endovenous laser ablation and microwave ablation for great saphenous varicose veins. Eur Rev Med Pharmacol Sci., 16(7):873-77.

6- NHS Choices(2012):. Varicose veins - Treatment. Available from: http://www.nhs.uk/ conditions/varicose-veins/pages/treatment.aspx.

7- Berridge D, Bradbury AW, Davies AH et al. (2011): Recommendations for the referral and treatment of patients with lower limb chronic venous insufficiency (including varicose veins). Phlebology, 26(3): 91-3.

8- Breu FX, Guggenbichler S, Wollmann JC (2008): 2nd European consenus meeting on Foam sclerotherapy Tegnersee, Germany. VASA., 37(S71): $1-29$.

9- Luebke $T$ and Brunkwall $J$ (2008): Systematic review and meta-analysis of endovenous radiofrequency obliteration, endovenous laser therapy, and foam sclerotherapy for primary varicosis. J Cardiovasc Surg (Torino), 49: $213-33$.
10- Pascarella L, Bergan JJ, Mekenas LV (2006): Severe chronic venous insufficiency Treated by foamed sclerosant. Ann Vasc Surg., 20 (1): 83 - 91.

11- Cavezzi A and Tessari L (2009): Foam sclerotherapy techniques: different gases and methods of preparation, catheter versus direct injection. Phlebology, 24: 247 51.

12- Bergan JJ, Schmid-Schonbein GW, Smith PD et al. (2006): Chronic venous disease. N Engl J Med., 355: 488-498.

13- Darke SG and Baker SJ (2006): Ultrasoundguided foam sclerotherapy for the treatment of varicose veins. Br J Surg., 93(8): 969 - 74.

14- Parsi K (2009): Catheter-directed sclerotherapy. Phlebology, 24: 98 - 10713.

15- Rigby KA, Palfreyman SJ, Beverley C, Michaels JA (2004): Surgery versus sclerotherapy for the treatment of varicose veins. Cochrane Database Syst Rev., 4(4), 1-6.

16- Gillet JL, Guedes JM, Guex JJ et al. (2009): Sideeffects and complications of foam sclerotherapy of the great and small saphenous veins: a controlled multicenter prospective study including 1,025 patients. Phlebology, 24:131-8.

17- Morrison N, Cavezzi A, Bergan J, Partsch H (2006): Regarding "Stroke after varicose vein foam injection sclerotherapy". J Vasc Surg., 44 (1): $224-5$.

18- Myers KA, Jolley D, Clough A, Kirwan J (2007): Outcome of ultrasound-guided sclerotherapy for varicose veins: medium-term results assessed by ultrasound surveillance. Eur JV asc Endovasc Surg., 33:116-21.

19- Smith CP (2005): Saphenous ablation: sclerosant or sclerofoam? Sem Vasc Surg., 18: $19-24$.

20- Cabrera J and Garcí-Olmedo A (2000): Treatment of varicose long saphenous veins with sclerosant in microfoam form: long-term outcomes. Phlebology, 15:19-23.

21- Tessari L, Cavezzi A, Frullini A (2001): Preliminary experience with a new sclerosing foam in the treatment of varicose veins. Dermatol Surg., 27:58-60.

22- Theivacumar NS, Darwood R, Gough MJ (2009): Neovascularization and recurrence 2 years after varicose vein treatment for sapheno-femoral and great saphenous vein reflux: a comparsion of surgery and endovenous laser ablation. Eur J Vasc Endovasc Surg., $\begin{array}{lllll}38 & \text { (2): } & 203 & - & 7\end{array}$ 